\title{
EVALUATION OF THE USABILITY OF THE ALKALI ACTIVATED INDUSTRIAL WASTES AS A MATRIX AND SUPPORT OF PHOTOCATALYSTS
}

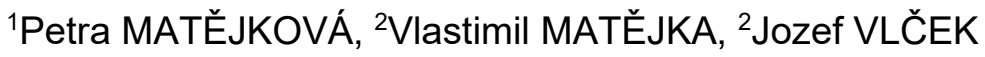 \\ ${ }^{1}$ VSB - Technical University of Ostrava, Centre for Advanced Innovation Technologies, Ostrava, \\ Czech Republic, EU, petra.matejkova@vsb.cz \\ ${ }^{2}$ VSB - Technical University of Ostrava, FMST, Department of Chemistry, Ostrava, Czech Republic, EU, \\ vlastimil.matejka@vsb.cz, jozef.vlcek@vsb.cz
}

https://doi.org/10.37904/nanocon.2019.8631

\begin{abstract}
The aim of this study was to evaluate the possibility of the metallurgical wastes (slags and fly ash) utilization as a support for photocatalyticaly active composites. Metallurgical slags (MS) represent large volume group of by-products originated during the metallurgical production processes. The fly ash (FA) is the group of the wastes coming from the power plants, which are also part of the big cast iron and steel production plants. Although several applications of MS and FA already exist, non-negligible part is still stored in the landfills and thus the searching for new applications of these wastes is on high demand. Alkali activation of MS and FA represents one of the possibilities of the re-utilization of these wastes, which enables the application of these materials as the inorganic binders in building industry. The combinations of the photocatalysts with cement based materials are intensively studied with the aim of their utilization for the photocatalytic cleaning of the air. In present work, the alkali activated MS was tested as the matrix for the photocatalyticaly active composite kaoline/ $\mathrm{TiO}_{2}$ and the alkali activated mixture of $\mathrm{MS}+\mathrm{FA}$ was evaluated as a support the deposition of $\mathrm{TiO}_{2}$ layer. The photodegradation activity of prepared samples against NOx was tested. The results identified the application of $\mathrm{TiO}_{2}$ layer on the surface of alkali activated mixture MS+FA as favourable with respect to NO conversion.
\end{abstract}

Keywords: Slag, alkali activation, $\mathrm{TiO}_{2}$, photocatalysts, photodegradation

\section{INTRODUCTION}

High amount of the wastes and by-products is produced by the metallurgy and energy industry and the building industry is the biggest consumer of these materials [1]. The blast furnace slag (BFS) and fly ash (FA) are widely used as the components of blended cements. Heavy aggregates produced from slowly cooled slags used for the road construction is the other example of the possible utilization of the by-products from the metallurgy. The requirement for the utilization of these materials as the alternative inorganic binders is high amount of $\mathrm{Al}_{2} \mathrm{O}_{3}$ and $\mathrm{SiO}_{2}$ in amorphous phase, which assure the ability of the so called latent hydraulic activity (LHA) [2]. Latent (hidden) hydraulic properties of these materials can be evoked by the addition of the suitable alkali activator and so called Alkali Activated Materials (AAM) originated. Latent hydraulic properties of the granulated blast furnace slag (GBFS) and fly ash are usually induced by the addition of the water glass.

The hardened products maturated in moist environment could exhibit even better properties (mechanical properties, chemical resistance) in comparison to the products prepared by the hydration of Ordinary Portland cement (OPC). OPC is an excellent hydraulic binder but its production is energetically demanding due to the necessity of the calcination of the raw materials in rotational furnace, other negative environmental aspects is the production of the high amount of $\mathrm{CO}_{2}$ [3]. The tuning of the alkali activation process of GBFS and FA is frequently studied in a number of scientific reports dealing with inorganic binders $[4,5]$. The result of the alkali activation is the formation of new phases, which have the dominant effect on the final mechanical properties, and chemical resistance of the hardened samples [6]. The properties of the final product are influenced also 
by the type of the alkali activator as well as by the process of the mixing of the tested AAM admixtures with alkali activator. The preparation of the tiles, curbs or the protection tiles placed at the road edges as well as the noise protective barriers represent the already tested real application of the alkali activated materials.

The air pollution is a serious problem and enormous effort is put to develop the procedures for the decreasing of its level. One of the often researched ways for the elimination of the hazardous substances from the air is their photocatalytic degradation [7]. Since the buildings, roofs, noise barriers but also the surface of the roads are in direct contact with the air, the utilization of the photocatalytic degradation process of the pollutants running on the surfaces of these construction parts represent an elegant way to improve the air quality. The most studied photocatalyst is $\mathrm{TiO}_{2}$ and its utilization in the building parts based on Portland cement has been already explored by many researchers for example [8-10]. The utilization of AAM as the support of photocatalyticaly active materials is not researched in such range as the materials based on OPC as the binder.

The aim of this work was to evaluate the possibility to utilize photocatalyticaly active materials in the combination with the hardened matrix based on the AAM. Two different approaches for the combination of $\mathrm{TiO}_{2}$ photocatalyst were tested. In the first approach, photocatalyticaly active composite kaoline/ $/ \mathrm{TiO}_{2}$ was used as the admixture of GBFS. And this mixture was activated with the sodium metasilicate and let to harden in the moist environment. In the second approach, $\mathrm{TiO}_{2}$ in the form of colloid sol was used to cover the surface of already hardened samples produced by the alkali activation of the mixture of GBFS and FA using water glass. The photocatalytic activity of prepared samples was tested by the photodegradation of $\mathrm{NO}_{2}$.

\section{MATERIALS AND METHODS}

Two different approaches of the $\mathrm{TiO}_{2}$ combination with LHA materials were tested. The first approach was based on the addition of kaoline/ $\mathrm{TiO}_{2}$ (KATI) composite in an amount of 15 and $25 \mathrm{wt} . \%$ into the powder GBFS and further mixed with granules of sodium metasilicate (NMS). The water was then added to this dry mixture and originated paste was formed into the mould made of steel and let to maturate $24 \mathrm{~h}$ in moist environment $\left(25^{\circ} \mathrm{C}, 99 \% \mathrm{RH}\right)$. After $24 \mathrm{~h}$ the samples were unmoulded and stored in the moist environment for selected time period $(2,7,28$ and 56 days). The composition of the samples is shown in Table 1. Since the composite $\mathrm{KATl}$ is based on the $\mathrm{TiO}_{2}$ particles anchored ion the surface of the kaolinite particles the samples containing only calcined kaoline (MK) were prepared in the same way and labelled as MK15 and MK25. The samples in a form of small cubes $(20 \times 20 \times 20 \mathrm{~mm})$ as well as in the form of tiles $(100 \times 50 \times 10 \mathrm{~mm})$ were prepared for the compressive strength tests and photocatalytic experiments.

Table 1 Composition of the GBFS samples

\begin{tabular}{|c|c|c|c|c|c|c|}
\hline \multirow{2}{*}{ Sample } & MK & KATI66 & FA & GBFS & $\mathrm{Na}_{2} \mathrm{O}$ & \multirow{2}{*}{ Water to solid ratio } \\
\hline & (g) & (g) & (g) & (g) & $\%$ & \\
\hline GBFS & 0 & 0 & 0 & 300 & \multirow{5}{*}{$2.5 / 5$} & 0.31 \\
\hline MK15 & 45 & 0 & 0 & \multirow{4}{*}{255} & & 0.34 \\
\hline MK25 & 75 & 0 & 0 & & & 0.36 \\
\hline KATI15 & 0 & 45 & 0 & & & 0.34 \\
\hline KATI25 & 0 & 75 & 0 & & & 0.36 \\
\hline GBFS_FA20 & 0 & 0 & 60 & 240 & \multirow{2}{*}{5} & 0.30 \\
\hline GBFS_FA40 & 0 & 0 & 120 & 180 & & 0.30 \\
\hline
\end{tabular}


The second approach comprises the samples based on the mixture of GBFS and FA prepared in the same way as the samples previously described with the exception that the mixture did not contain $\mathrm{TiO}_{2}$ photocatalyst. The samples were labelled GBFS_FA20 and GBFS_FA40 where the number signalizes the FA content, the composition of the samples is shown in Table 1. After 28 days of maturation in moist environment, the samples in a form of tiles were further stored in laboratory conditions $\left(25^{\circ} \mathrm{C}, 30 \%\right.$ of $\left.\mathrm{RH}\right)$ for additional 14 days to let them dry slowly. After that, the $\mathrm{TiO}_{2}$ suspension was applied on the surface of the tiles by the dipping of the tile into the $\mathrm{TiO}_{2}$ suspension for $10 \mathrm{~s}$. After that, the sample was let to dry for additional $4 \mathrm{~h}$. Then the samples were thermally treated in a muffle furnace for $2 \mathrm{~h}$ at $450^{\circ} \mathrm{C}$. The whole process was applied three times.

The compressive strength test was performed for the samples in a form of cubes after their maturation for 2 , 7, 28 and 56 days long hydration on the compression strength tester Compact 20/160 (Brio Hranice).

Apparatus and the conditions used for NO photodegradation experiment are in agreement with requirements given by international standard ISO 22197-1:2007. The scheme of the apparatus is shown in Figure 1.

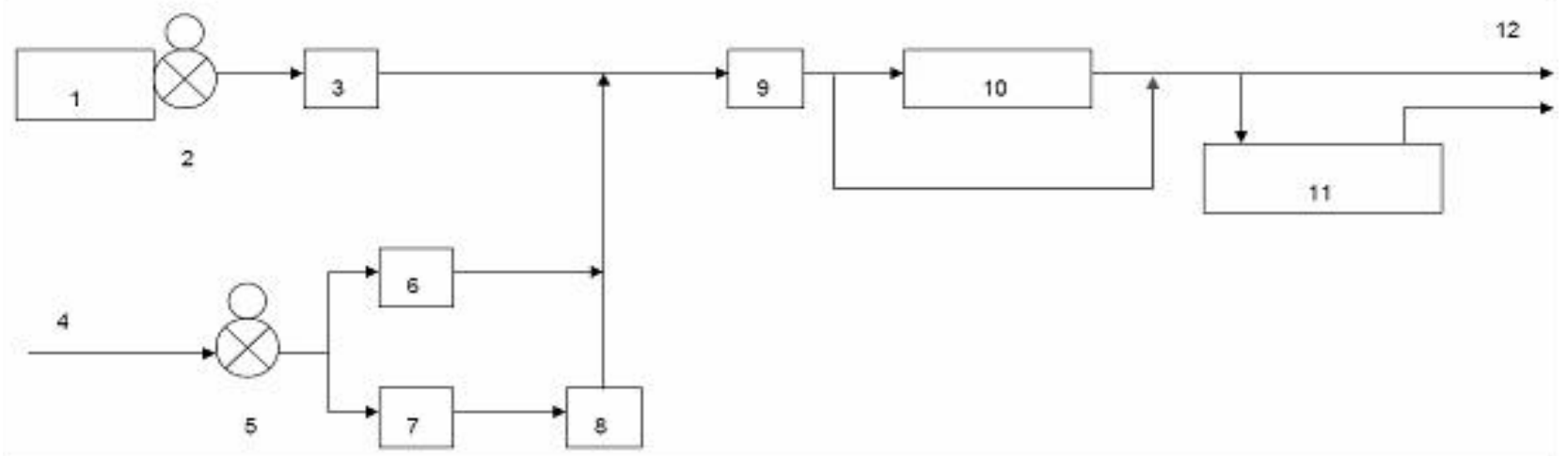

Figure 1 The scheme of the apparatus used for the NOx photodegradation test (1. Gas cylinder with mixture of $\mathrm{N}_{2}+\mathrm{NO}, 2 ., 5$. Reducing valves; 3., 6., 7. Mass flow controller, 4. Inlet of the pressurized air, 8. Glass wash bottle, 9. The cell for the RH measurement, 10. Photoreactor with UV lamp, 11. NOx analyser, 12. Outlet of the gas mixture)

NO was used as a model pollutant during the experiment and its initial stream dosed using mass flow controllers was mixed with air to give the final concentration $1.2 \mathrm{ppm}$. HORIBA APNA-370 analyzer was used for the detection of NO concentration. The flow rate of the inlet gas mixture through the reactor was $31 \cdot \mathrm{min}^{-1}$. OSRAM EVERSUN L4OW/79K tube was used as a source of UV irradiation during the photodegradation tests. The UV light intensity (measured at $356 \mathrm{~nm}$ ) was $10 \mathrm{~W} \cdot \mathrm{m}^{-2}$. The relative humidity was kept at the value $49.7 \pm$ $0.3 \%$ during the measurement. The experiments were performed in shortened $60 \mathrm{~min}$ long irradiation period.

\section{RESULTS}

The effect of the amount of $\mathrm{Na}_{2} \mathrm{O}$ in the activator on the compressive strength of the samples is shown in Figure 2. Application of the activator with $2.5 \mathrm{wt} . \%$ of $\mathrm{Na}_{2} \mathrm{O}$ to GBFS let to develop the compressive strength value close to $80 \mathrm{MPa}$ after 58 days long hydration. In the case of alkali activated mixtures of GBFS with MK or KATI composite the compressive strength reached very low values, which did not exceed $4 \mathrm{MPa}$ (Figure 2a), the development of the compressive strength was the same for all of the tested samples regardless the type of the admixture used. Increasing of the $\mathrm{Na}_{2} \mathrm{O}$ amount to $5 \mathrm{wt}$ \% caused the formation of the samples with obviously higher values of compressive strength as evident from Figure $\mathbf{2 b}$. Again the highest compressive strength around $80 \mathrm{MPa}$ after 58 days of hydration was achieved for pure GBFS followed by the sample of GBFS with $15 \mathrm{wt} . \%$ of KATI admixture which reached approximately $40 \mathrm{MPa}$ after the 58 days long hydration. 
By the comparison of the compressive strength values obtained for the samples with MK and KATI admixtures (Figure 2b) the positive effect of the $\mathrm{TiO}_{2}$ in the KATI composite was observed (Figure 2b). Lower amount of the admixtures is preferable for achieving of the higher compressive strength values (compare the series MK15 and MK25 and KATI15 and KATI25 in Figure 2b). The addition of the FA to the GBFS let to form the samples with obviously higher compressive strength, in comparison to pure GBFS, as evident from Figure 3 . These mixtures were used for the preparation of the samples for which the $\mathrm{TiO}_{2}$ was applied in a form of thin layers.
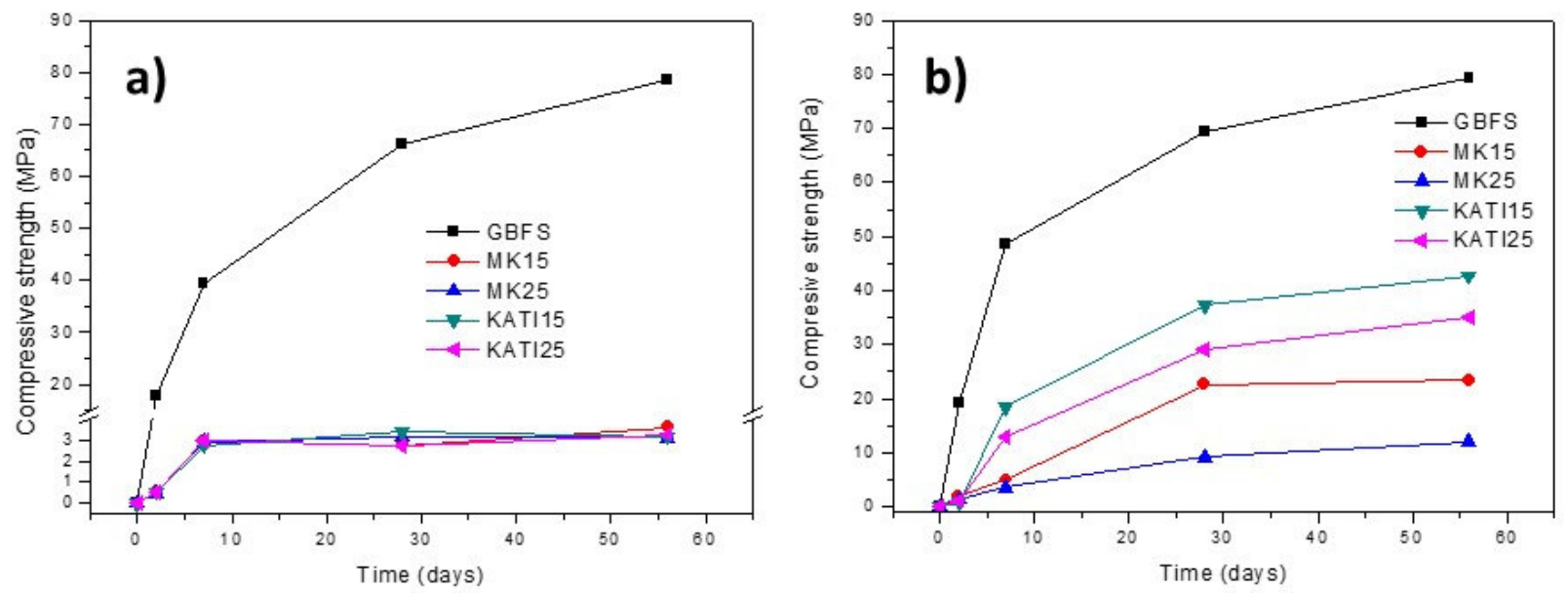

Figure 2 The time evolution of the compressive strength of the samples activated with the sodium silicate in amount carrying a) 2.5 wt. $\%$ of $\mathrm{Na}_{2} \mathrm{O}$ and b) 5 wt.\% of $\mathrm{Na}_{2} \mathrm{O}$

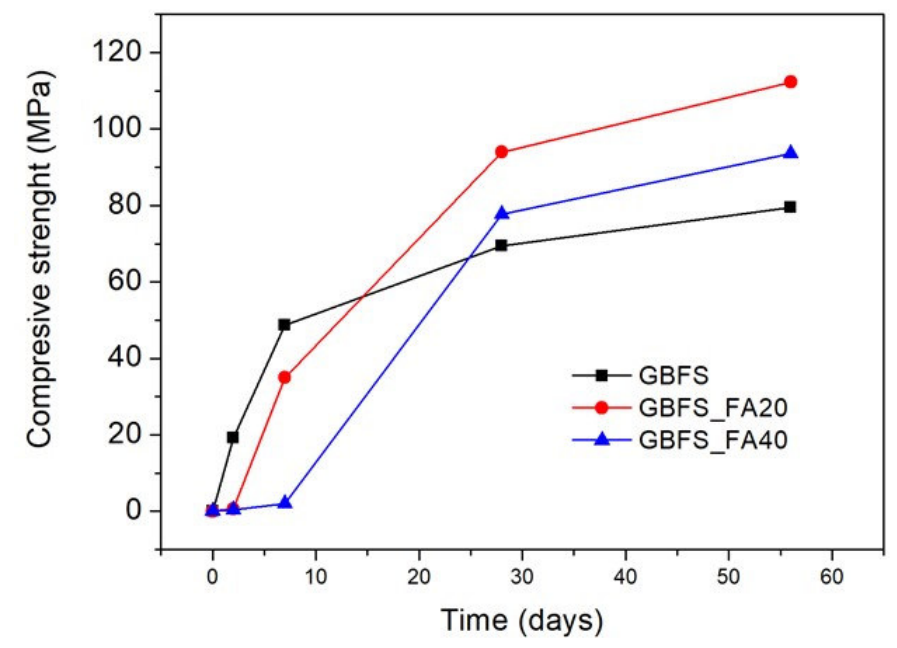

Figure 3 The time evolution of the compressive strength of the GBFS mixtures with FA

The degree of NO conversion caused by 60 min long UV irradiation of the samples with the presence of photocatalytic active $\mathrm{TiO}_{2}$ is shown in Figure 4.

The conversion of the NO is negligible for the series of the samples with KATI composite as evident from Figure 4. Activation of the GBFS+KATI mixture using higher amount of alkali activator carrying $5 \mathrm{wt} . \%$ of $\mathrm{Na}_{2} \mathrm{O}$ caused higher NO conversion compared with the samples activated with sodium metasilicate carrying $2.5 \mathrm{wt} \%$ of $\mathrm{Na}_{2} \mathrm{O}$ as evident from Figure 4. Higher conversion for sample KATI_25 is related to higher content of $\mathrm{TiO}_{2}$ in this sample. 
Application of $\mathrm{TiO}_{2}$ in a form of thin layers was responsible for the enhancement of $\mathrm{NO}$ conversion which reached approximately $6 \%$ in the case of the tiles prepared from the mixture of $60 \mathrm{wt} . \%$ of GBFS and $40 \mathrm{wt} . \%$ of FA. The positive effect of higher amount of FA on the NO conversion was observed (Figure 4) and could be attributed to enhanced fixation of $\mathrm{Na}+$ ions in hydration products originated in the presence of $\mathrm{FA}$.

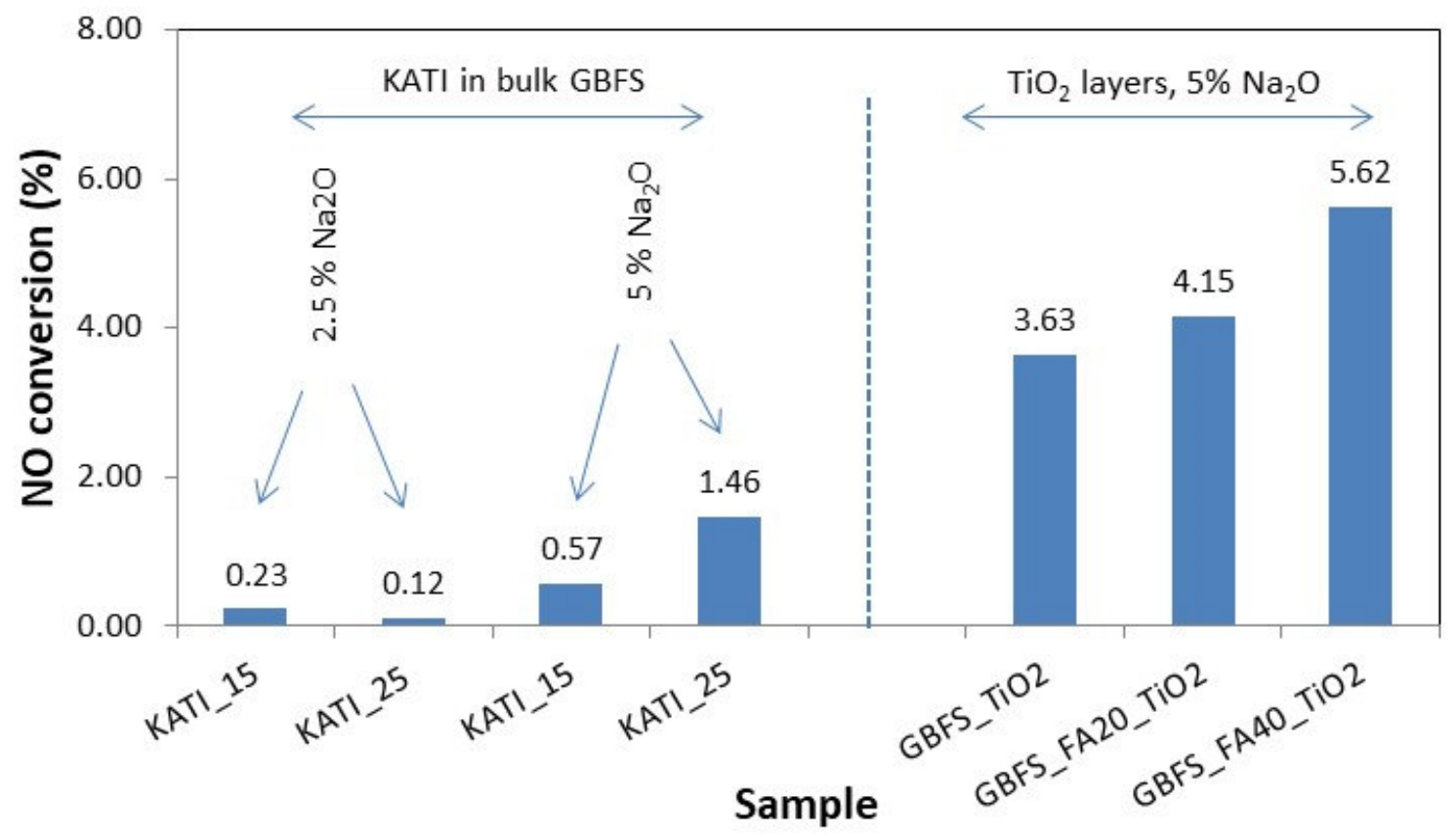

Figure 4 Comparison of the degree of NO conversion for the samples with composite KATI and the samples of tiles with the $\mathrm{TiO}_{2}$ applied as the layer

\section{CONCLUSION}

The samples of alkali activated granulated blast furnace slags and its mixtures with i) kalcined kaoline, ii) photocatalyticaly active composite KATI and iii) fly ash were prepared. The compressive strength values of the alkali activated mixtures of GBFS with MK and KATI revealed the importance of higher amount of alkali activator for higher strength of the mixtures with KATI. The positive effect of the $\mathrm{TiO}_{2}$ presence was also observed. The addition of fly ash to the GBFS and subsequent alkali activation of the mixtures let to form hardened samples with even higher compressive strength. The tests of NO conversion revealed higher NO conversion for the samples with $\mathrm{TiO}_{2}$ present in a form of thin layers. The positive effect of the amount of fly ash on the NO conversion was observed. The further experiments will be focused on the alkali activated samples with the different photocatalyst applied in a form of thin layers.

\section{ACKNOWLEDGEMENTS}

This work was supported by the EU Regional Development Fund within the Operational Programme Research, Development and Education under the aegis of Ministry of Education, Youth and Sports of the Czech Republic; Project number CZ.02.1.01/0.0/0.0/17_049/0008426.

\section{REFERENCES}

[1] NIDHEESH, P.V, KUMAR, M. Suresh, An overview of environmental sustainability in cement and steel production, Journal of Cleaner Production, Volume 231, 2019, p. 856-871. 
[2] KRIVENKO, Pavel.V., KOVALCHUK, G. Yu. Directed syntesis of alkaline aluminosilicate minerals in geocement matrix. Journal of Materials Science, 2007, vol. 42, no. 9, p. 2944-2952.

[3] CHEN, Cong, HABERT, Gullaume, BOUZIDI, Youcef, JULLIEN, Agnès. Environmental impact of cement production: detail of the different processes and cement plant variability evaluation. Journal of Cleaner Production, 2010, vol. 18, no. 5, p. 478-485.

[4] WANG, Chaohui, WEN, Penghui, WANG, Menghao, FAN, Qiaojuan, WANG, Xinqi. Preparation and characterization of road alkali-activated blast furnace slag paste, Construction and Building Materials, Volume 181,2018 , p. 175-184.

[5] GIERGICZNY, Zbigniew. Fly ash and slag, Cement and Concrete Research, Volume 124, 2019, 105826.

[6] VLČEK, Jozef, DRONGOVÁ, Lucie, TOPINKOVÁ, Michaela, MATĚJKA, Vlastimil, KUKUTSCHOVÁ, Jana, VAVRO, Martin, TOMKOVÁ, Václava. Identification of phase composition of binders from alkali-activated mixtures of granulated blast furnace slag and fly ash. Ceramics-Silikáty. 2014, 58(1), 79-88. ISSN 0862-5468.

[7] JIANG, Qiwen, QI, Tiantian, YANG, Ting, LIU, Yanhua. Ceramic tiles for photocatalytic removal of NO in indoor and outdoor air under visible light, Building and Environment, Volume 158, 2019, p. 94-103.

[8] KOVÁŘ, Pavel, LACNÝ, Zdeněk, PŘIKRYL, Jan, MATĚJKA, Vlastimil. The route for the decreasing of air pollutants using photocatalysis over titanium dioxide incorporated in to different kinds of concrete surfaces. Transport, Health and Environment, 2.-3. 11. 2010, Blansko. Brno: Tribun EU s.r.o., 2010, p. 133-138.

[9] MATĚJKA, Vlastimil, KOVÁŘ, Pavel, BÁBKOVÁ, Petra, MAMULOVÁ-KUTLÁKOVÁ, Kateřina, PŘIKRYL, Jan, ČAPKOVÁ, Pavla. Utilization of Photoactive Kaolinite/TiO 2 Composite. Cement-Based Building Materials. In Nanotechnology in Construction 3, 31.5. 2009, Praha. Berlin/Heidelberg: Springer, 2009, p 309-314. ISBN: 978-3642-00979-2.

[10] MATĚJKA, Vlastimil, MATĚJKOVÁ, Petra, KOVÁŘ, Pavel, VLČEK, Jozef, PŘIKRYL, Jan, ČERVENKA, Pavel, LACNÝ, Zdeněk, KUKUTSCHOVÁ, Jana. Metakaolinite/TiO 2 composite: Photoactive admixture for building materials based on Portland cement binder. Construction and Building Materials, 2012, vol. 35, p. 38-44. 